\title{
Baju Kurung Pakaian Tradisional Perempuan Melayu Jambi
}

\author{
Fatonah Nurdin ${ }^{*}$, Hartati ${ }^{2}$, Selfi Mahat Putri ${ }^{3}$ \\ ${ }^{1,2,3}$ Prodi Ilmu Sejarah Fakultas Keguruan dan Ilmu Kependidikan Universitas Jambi \\ *Correspondence email: fatonah.nurdin@unja.ac.id
}

\begin{abstract}
Abstrak. Penelitian ini akan melihat pada kajian Budaya Melayu Jambi dari sudut pandang baju kurung sebagai pakaian tradisional perempuan melayu Jambi. Dengan menggunakan metode penelitian kualitatif dengan pendekatan sejarah. Penelitian ini bertujuan untuk mengetahui sejarah dan makna nilai-nilai filosofi baju kurung dengan perkembangannya secara etika dan estetika sebagai pakaian tradisiona perempuan melayu Jambi. Manfaat dari penelitian ini diharapkan bisa menjadi salah satu inventarisasi budaya melayu Jambi dalam ranah ilmiah. Dengan latar belakang keanekaragaman kekayaan alam dan budaya yang dimiliki oleh provinsi Jambi, terdapat nilai-nilai keindahan, fasafah dan nilai-nilai estetika budaya, salah satunya etika dan estetika dalam berpakaian merupakan bagian penting dalam pakaian tradisional perempuan melayu Jambi. Baju kurung sebagai simbol perempuan muslimah melayu Jambi makna filosofi yang erat dengan adat tradisi dan Islam. masuknya Islam di tanah melayu Jambi mempengaruhi konsep dalam berpakaian prempuan melayu Jambi. Dapat disimpulkan baju kurung merupakan cerminan jati diri perempuan muslimah melayu Jambi sesuai dengan syariat Islam tergambarkan dalam seloko adat Jambi "adat bersendi syara', syara' bersendi kitabullah. Syara' mengato, adat memakai." Seloko adat tersebut menjadi nilai filosofi dalam seni berpakaian perempuan melayu Jambi yang memiliki ke unikan dari nilai etika dan estika tanpa mengurangi keanggunan perempuan melayu Jambi.
\end{abstract}

Keyword: Baju kurung; pakaian adat; perempuan melayu; Jambi

Abstract. This research would focus on studying of Jambi Malay Culture from the point of view baju kurung as the traditional clothing of Jambi Malay women. By using qualitative research methods with a historical approach, this study aimed to determine the history and meaning of the philosophical values of baju kurung with its development ethically and aesthetically as the traditional clothing of Jambi Malay women. The benefits of this research were expected to become an inventory of Jambi Malay culture in the scientific studies. In the background of the diversity of natural and cultural wealth owned by Jambi province, there were many kinds of values of beauty, philosophy and cultural ethical and aesthetic values, one of them was an aesthetics in clothing which was important part of traditional Jambi Malay women's clothing. Baju kurung as a symbol of Jambi Malay Muslimah women have a philosophical meaning that was closely related to traditional and Islamic customs. The entry of Islam in the land of Malay Jambi influenced the concept of dressing up in Jambi's Malay women. It can be concluded that baju kurung was a reflection of the identity of Muslimah women in Jambi, according to Islamic law, which is described in the seloko of custom Jambi "adat bersendi syara', syara' bersendi kitabullah. Syara' mangato, adat memakai. "The seloko of custom Jambi has become a philosophical value in the art of dressing Jambi Malay women which has the uniqueness of ethical and aesthetic values without reducing the elegance of Jambi Malay women.

Keyword: Baju kurung; Traditional clothes; Malay women; Jambi

\section{PENDAHULUAN}

Masyarakat Provinsi Jambi mayoritas beragama Islam baik yang berdomisili di kota mau pun di perdesaan. Terbentuknya nilai-nilai luhur budaya masyarakat Jambi tidak lepas dari pengaruh nilai Islam yang dijunjung tinggi oleh masyarakat daerah Jambi, hal tersebut dijadi kan pedoman dalam pergaulan sehari yang diimplementasikan dalam kehidupan bermasyarakat. Kuntjaraningrat mengatakan, "nilai-nilai budaya merupakan konsep-konsep yang hidup dalam alam pikiran sebagian masyarakat mengenai hal-hal yang harus mereka anggap amat bernilai dalam hidup. Karena itu sistem nilai budaya biasanya berfungsi sebagai pedoman tertinggi bagi kelakuan manusia. Sistem-sistem tata kelakuan manusia lain yang tingkatnya lebih kongkrit seperti aturan khusus dan norma-norma yang berpedoman pada sistem nilai budaya terebut" (Lembaga Adat Provinsi Jambi, 2001).
Budaya masyarakat melayu Jambi sangat kental dengan ajaran Islam termasuk di dalamnya tata cara berpakaian yang dilandasi oleh prinsip dasar adat Jambi sendiri yang berlandaskan pada seloko adat "adat bersendi syara', syara' bersendi kitabullah" dari seloko adat tersebut terlihat prinsip dasar masyarakat melayu Jambi yang dapat dipahami bahwa budaya Islam melatar belakangi segala bidang kehidupan masyarakat adat Jambi termasuk cara berpakaian mereka. Tata cara berpakaian dalam Islam adalah menutupi aurat, terutama bagi wanita yang ketentuannya adalah menutupi kepala dan seluruh tubuh.

Pakaian merupakan kulit sosial dari kebudayaan. Pakaian menurut Henk Schulte merupakan "suatu ekspresi dari identitas seseorang, pakaian juga berperan besar dalam menentukan citra seseorang. Sadar atau tidak sadar, mau atau tidak mau, kita menaruh harapan besar bahwa pakaian dapat menggambarkan dengan jelas identitas kita." (Dwi Ratna N, 2013). 
Pakaian adat daerah Jambi pada dasarnya terdiri dari pakaian bangsawan dan pakaian priyayi serta pakaian suku-suku ataupun kelompok masyarakat adat yang tersebar diseluruh provinsi Jambi dengan segala ragamnya (Lembaga Adat Provinsi Jambi, 2001). Pakaian adat dalam budaya melayu Jambi terdiri dua macam. Salah satu pakaian adat untuk para wanita dalam budaya melayu Jambi dalam hal ini yaitu baju kurung perempuan melayu Jambi.

Baju kurung merupakan ekspresi dari identitas perempuan melayu Jambi yang berlandaskan syariat Islam menutup seluruh tubuh namun masih tetap nyaman dan indah saat dipakai oleh perempuan melayu.

Pakaian adat melayu Jambi, memiliki beberapa jenis dan fungsi yaitu jenis dan fungsi pakaian seharihari dan jenis dan fungsi pakaian adat resmi yang biasa dikenakan dalam acara-acara khusus/resmi. Untuk pakaian baju kurung sehari-hari perempuan melayu Jambi biasa menggunakan baju kurung yang sederhana dan tidak mencolok dibandingkan dengan pakaian baju kurung untuk acara adat resmi yang biasanya bersulam emas dan berbahan beludru.

\section{Sejarah Baju Kurung}

Pakaian merupakan bagian penting dalam sejarah kehidupan manusia. Merupakan kebutuhan pokok selain tempat tinggal dan makanan. Walaupun dalam sejarahnya, pakaian hanya digunakan untuk tujuan melindungi atau menutup tubuh dengan menggunakan bulu hewan, kulit hewan, daun ataupun rumput yang diikatkan. Namun, seiring perkembangan zaman untuk melindungi tubuh telah menggunakan potongan kain yang terjahit dengan benang yang kita kenal dengan istilah pakaian atau disebut juga "baju" dengan beragam model dan gaya (Annisa Mardiani, 2018).

Perkembangan yang cukup pesat juga membuat pakaian berubah status. Tidak hanya sekedar pelindung atau penutup tubuh, tetapi telah menjadi kebutuhan gaya hidup yang memperlihatkan status, kelas sosial, bahkan identitas etnis dan agama seseorang. Hal inilah yang menjadi menarik mengkaji mengenai baju kurung sebagai baju tradisional perempuan melayu Jambi. Perkembangan Jenis pakaian tergantung pada adat istiadat, kebiasaan dan budaya yang memiliki ciri khas masing-masing (Dwi Ratna Nurhajarani, 2013).

Baju kurung adalah salah satu pakaian adat tradisional masyarakat Melayu baik itu Indonesia, Brunei Darussalam, Malaysia, Singapura, dan Thailand bagian selatan. Baju kurung sering dilekatkan dengan kaum perempuan. Menurut sejarah, catatan dari Tiongkok di mengabarkan bahwa masyarakat Melayu baik perempuan maupun lelaki di abad ke-13 hanya mengenakan penutup tubuh bagian bawah. Dalam perkembangannya, perempuan Melayu memakai sarung dengan model "berkemban" yakni melilitkan sarung di sekeliling dada. Celana juga mulai dipakai, dengan model "Gunting Aceh" yaitu celana yang panjangnya hanya sedikit di bawah lutut.

Namun kemudian perdagangan membawa pengaruh budaya asing. Barang-barang dari Tiongkok, India, dan Timur Tengah berdatangan. Selain perniagaan, hal ini juga memaparkan masyarakat Melayu kepada cara berpakaian orang-orang asing tersebut. Orang Melayu juga mengadopsi Islam sebagai agama mereka, dan ini memengaruhi cara berpakaian karena di dalam agama baru ini terdapat kewajiban untuk menutup aurat baik bagi perempuan maupun laki-laki. Puncaknya adalah pada tahun 1400-an, di mana pakaian Melayu digambarkan dengan jelas dalam karya kesusasteraan Sejarah Melayu (Malay Annals).

Di sinilah kita dapat melihat kemunculan baju kurung, di mana sudah mulai lazim bagi orang Melayu untuk memakai semacam tunik untuk menutupi tubuh mereka. Tunik adalah pengaruh dari timur tengah, ditunjukkan dalam bentuk kerah baju yang dipakai oleh orang Arab. Menurut Judi Achjadi dalam buku "Pakaian Daerah Wanita Indonesia", baju kurung diperkenalkan oleh pedagang-pedagang Islam dan India barat. Ini terlihat dari leher berbentuk tunik. Baju kurung pada masa Malaka pada awalnya berpotongan ketat dan juga pendek. Konon, Tun Hassan merupakan orang yang mengubah potongan baju kurung menjadi lebih longgar dan panjang. Menurut Dato' Haji Muhammad Said Haji Sulaiman dalam buku "Pakaian Patut Melayu", baju kurung seperti yang kita kenal sekarang berasal dari masa pemerintahan Sultan Abu Bakar pada tahun 1800 di Teluk Belanga, Singapura. Sementara Mattiebelle Gettinger menjelaskan bahwa baju kurung telah dipakai oleh penari istana di Palembang dan telah menjadi jenis pakaian populer di Sumatera pada abad ke-20.

Menurut ketua Lembaga Adat Melayu provinsi Jambi, H. Hasip Kalimudding Syam (81), "sejarah lahirnya baju kurung melayu Jambi tidak terlepas dari pengaruh masuknya agama Islam di negeri Jambi pada masa kerajaan melayu. Masuknya ajaran Islam yang dibawa oleh para pedagang dari Timur Tengah sedikit banyaknya mempengaruh cara berpakaian masyarakat melayu Jambi, yang menyesuaikan dengan syariat Islam yaitu menutupi aurat." (Wawancara, Jambi, Rabu, 1 Juli 2020). Hal senada juga dikemukakan oleh ketua Lembaga Adat Kota Jambi, H. Azra'i Al-Basri (69) "baju kurung dikenal oleh masyarakat melayu Jambi setelah masuknya agama Islam ke Jambi, pada awalnya pakaian perempuan melayu Jambi dahulunya terbuat dari kain goni dan tidak menutupi aurat, hanya menutupi bagian tertentu saja, dengan masuknya pengaruh Islam dan perkemmbangan agama Islam di Jambi maka setelah abad 15 masyarakat mulai mengenal pakaian secara syariat Islam, termasuk pakaian perempuanya harus sesuai dengan syariat Islam." (wawancara, Jambi, kamis, 2 Juli 2020). Sementara, Kepala museum Singinjai, Nurlaini (2017) juga menuturkan bahwa " baju kurung melayu Jambi merujuk pada pakaian tradisional Arab 
dan China, pada abad 4 - 7 Masehi sudah ada masuk pengaruh Arab dan China. Pada masyarakat melayu Tua terlihat pakaian mereka merupakan pengaruh dari Arab, China dan kemudian masuk pengaruh India.". (wawancarra, Jambi, Kamis, 2 Juli 2020).

Menurut Nurlaini (2017), setelah masuknya agama Islam di tanah melayu Jambi, masyarakat melayu Jambi terkenal dengan budaya dan keyakinan yang kuat pada ajaran agama Islam. Sehingga antara adat dan ajaran Islam dalam kehidupan masyarakat Jambi selalu sejalan dengan pedoman hidupnya. Hal ini tercermin dalam seloko adat yang menjadi pedoman yaitu "adat bersendi syara', syara' bersendi kitabbullah" yang berarti yang semula berawal dari "adat bersendi layak dan patut". Kini layak dan patut adalah dalam ukuran simbolnya berdasarkan ketentuan agama Islam yaitu Syara' dan Kitabbullah (Nurlaini, 2017).

Pakaian adat perempuan melayu Jambi sesuai dengan agama yang mereka anut, umumnya perempuan dewasa melayu Jambi menutup aurat. Baju kurung yang menjadi ciri khas perempuan melayu Jambi memenuhi kreteria tersebut.

Ciri khas baju kurung adalah rancangan yang longgar pada lubang lengan, perut, dan dada. Pada saat dikenakan, bagian paling bawah baju kurung sejajar dengan pangkal paha, tetapi untuk kasus yang jarang ada pula yang memanjang hingga sejajar dengan lutut. Baju kurung tidak dipasangi kancing, Baju kurung tidak pula berkerah, tiap ujungnya direnda. Beberapa bagiannya sering dihiasi sulaman berwarna keemasan.

Mulanya, baju kurung biasa dipakai untuk upacara kebesaran melayu oleh kaum perempuan di dalam kerajaan, dipakai bersama-sama kain songket untuk dijadikan sarungnya, aneka perhiasan emas, dan tas kecil atau kipas. Karena sebagian besar masyarakat melayu memeluk Islam, banyak perempuan pengguna baju kurung yang menyerasikannya dengan jilbab, meskipun demikian terdapat juga yang tidak menggunakannya. Kini baju kurung banyak dipakai oleh masyarakat biasa, digunakan anak-anak untuk mengaji, atau ibu-ibu untuk ke pasar, tanpa disertakan pernak-pernik yang terkesan mewah.

\section{Filosofi Baju Kurung}

Baju Kurung mempunyai makna filosofi yang dalam. Ketika seseorang memakai baju kurung, maka ia sudah terikat dengan perbagai macam aturan atau ramburambu yang seharusnya dipatuhi. Baju Kurung mengandung makna orang yang memakainya di "kurung" dikukung oleh adat dikurung oleh syarak yaitu syariat Islam. Orang tua-tua mengingatkan ;apabila memakai pakaian Melayu, jaga pelihara aib dan malu. Apabila memakai baju Melayu, duduk jangan membuat malu, tegak jangan mencari seteru, berjalan jangan mengharu biru, bercakap jangan lidah berbulu.

Ada beberapa hal yang harus diperhatikan ketika memakai baju kurung, yaitu : a. baju Melayu itu hendaklah melambai-lambai ditiup angin.

b. baju Melayu itu pantang mendedahkan aib badan, pantang menyingkap malu diri.

c. baju melayu itu hendaklah menutup aurat seperti kata pepatah apabila memakai membuka aurat, tanda hidup tidak beradat.

Dalam budaya Melayu terdapat tiga jenis pakaian untuk kaum lelaki. Berikut ini perian ketiga jenis pakaian itu.

a. Baju Gunting Cina

b. Baju Teluk Belanga

c. Baju Cekak Musang

Sedangkan Kaum perempuan Melayu memiliki dua jenis pakaian.

a. Baju kurung

b. Baju belah labuh (kebaya panjang).

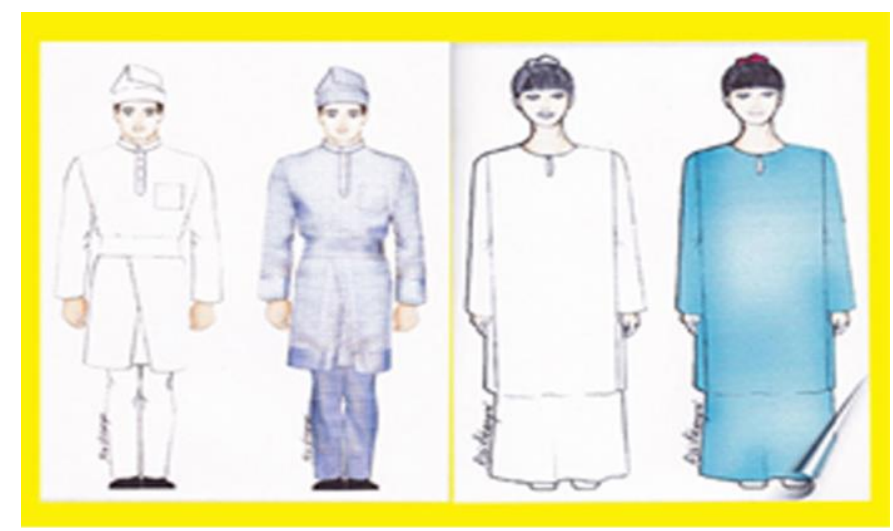

Gambar 1. Baju Kurung Melayu Jambi

Pada baju kurung melayu Jambi memiliki banyak makna nlilai filosofi yang melekat, seperti yang dikemukakan oleh Nurlaini (2017), baju kurung yang melekat pada perempuan melayu Jambi memiliki banyak nilai-nilai filosofis mulai dari atas sampai kebawah.
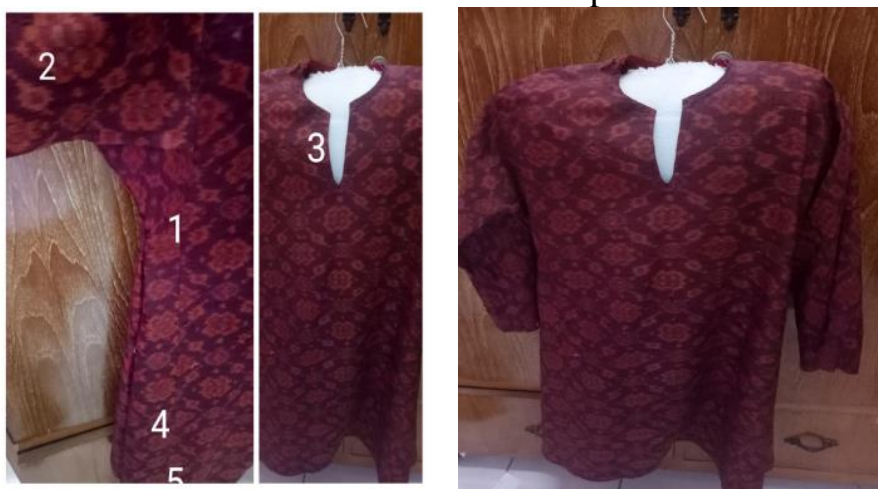

Gambar 2. Baju Kurung Perempuan Melayu Jambi

Contoh: baju kurung sehari-hari perempuan melayu Jambi di museum singinjai Jambi. Dok. Pribadi.

Nilai-nilai makna filosofi pada baju kurung melayu Jambi sebegai berikut:

1. Garis di atas pinggang tersebut dimaknai bahwa setiap pengeluaran rumah tangga wanita yang mengatur. 
2. Lengan tangan yang lurus, dimaknai bahwa kemampuan yang terjangkau, segala sesuatu harus sesuai dengan kemampuan yang tejangkau, artinya tidak boleh besar pasak daripada tiang.

3. Pada leher kebuka $25 \mathrm{~cm}$ melambangkan 25 nabi dan rasul yang menjadi panutan umat muslim yang harus menjadi tauladan.

4. Panjang ke bawah $5 \mathrm{~cm}$ diatas lutut melambangkan bahwa si pemakai merupakan perempuan bebas tidak terikat, artinya belum atau sedang tidak dalam ikatan pernikahan, yang berarti bebas bergerak.

5. Panjang ke bawah $5 \mathrm{~cm}$ di bawah lutut melambangkan bahwa si pemakai telah terikat oleh aturan, telah menikah harus menjaga nama baik suami dan keluarga.

Demikianlah filosofi yang dimaknai pada baju kurung perempuan melayu Jambi, seperti yang dituturkan oleh kepala museum Siginjai Jambi. (wawancara, Kota Jambi, 2 Juli 2020).
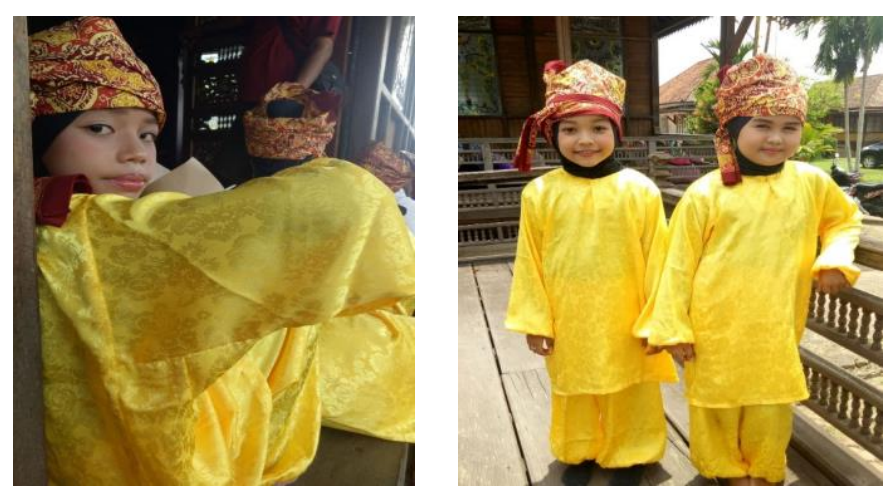

Gambar 3. Baju Kurung Anak Melayu Jambi

Keterangan: contoh baju kurung yang dipakai anak-anak dalam kegiatan kegiatan kesenian bungo krinok. Baju kurung yang dipandankan dengan bawahan celana panjang dan atasan jilbab dan tengkuluk, dengan baju kurung tsb anak-anak tetap luwes bergerak, dan sedari dini anak perempuan melayu Jambi sudah dikenalkan dengan baju kurung guna melestarikan baju kurung sebagai warisan budaya melayu Jambi.

Baju kurung melayu tidak hanya berfungsi sebagai pembalut tubuh secara adat tetapi juga pembungkus aurat secara syarak dalam syariat Islam sesuai dengan falsafah adat Jambi "adat bersendi syarak, syarak bersendi kitabullah. Syarak mengato, adat memakai." Bagi masyarakat melayu anak-anak perempuan sedini mungkin sudah diperkenalkan dangan adat dan syarak. Salah satunya adalah mengenal rasa malu, sehingga anak-anak perempuan dibiasakan dan diajarkan tuk menutup aurat seperti menggunakan pakaian yang tertutup.

\section{Perkembangan Baju Kurung}

Dalam beberapa sumber dikatakan bahwa baju kurung melayu Jambi mengalami perkembangan yang cukup pesat. Pada awalnya, baju kurung digunakan sebagai pakaian harian bagi perempuan maupun laki-laki masyarakat Melayu Jambi. Hal ini terlihat dari foto-foto klasik pada abad ke-19 dan awal abad ke-20 dimana terlihat perempuan dan laki-laki menggunakan baju kurung dengan tengkuluk dan teluk belango untuk bekerja di sawah, ladang atau humo mencari kayu dan menjunjung bawaan di atas kepala. Selain itu juga disebutkan, penyerahan pusaka keris Singo Marjayo pegangan Pangeran Ratu kepada Asisten Residen Pemerintah Hindia Belanda di Jambi tahun 1906 terlihat pihak Ratu mengenakan busana teluk belango. Demikian juga dalam foto saat perempuan melayu Jambi memintal benang atau atau acara-acara di desa menggunakan baju kurung dan tengkuluk (Junaidi T Noor, 2010).

Penggunaan baju kurung pun mengalami perubahan fungsi, hal ini tergerus dengan semakin banyaknya industri tekstil dan pakaian yang lebih mudah dan praktis dengan beragam mode dan gaya. Sehingga fungsi dan kegunaan baju kurungpun mengalami kemunduran. Masyarakat Jambi mulai jarang menggunakan. Penggunaan baju kurung hanya pada saat acara-acara Adat dan kegiatan tertentu.

Melihat kondisi inilah, pemerintah daerah berupaya untuk melakukan upaya pelestarian dan pengembangan agar pakaian baju kurung sebagai pakaian tradisional Melayu Jambi tidak hilang di telan zaman. Gubernur Provinsi Jambi mengeluarkan surat keputusan No. 395/KEP.GUB/ORANG/2009 tertanggal 15 Januari 2010 telah menetapkan pakaian khas Melayu Jambi berupa teluk belango dengan kopiah hitam bagi laki-laki dan baju kurung pakai tengkuluk dengan aksesoris daerah sebagai pakaian dinas semua karyawan/ti di lingkungan Satuan Kerja Perangkat Daerah Provinsi Jambi pada setiap hari Rabu. Himbauan ini direspon cukup baik oleh Bupati/Walikota dan beberapa lembaga serta instansi vertikal, BUMN di wilayah Provinsi Jambi.

Meskipun perkembangan baju kurung mengalamin perubahan secara artisika namun secara etika tetap sesuai dengan syariat agama islam yaitu menutupi aurat wanita tidak telau menampakan lekuk tubuh wanita dewasa. Oleh karena itu biasa pemakaian baju kurung oleh perempuan melayu Jambi dilengkapi dengan kain batik atau kain songket sebagai bawahannya dan memakai penutup kepala tengkuluk atau pun jilbab sebagai penutup kepala.

Estetika adalah salah satu cabang fisafat yang membahas keindahan. Estetika merupakan ilmu membahas bagaimana keindahan bisa terbentuk, dan bagaimana supaya dapat merasakannya. Pembahasan lebih lanjut mengenai estetika adalah sebuah filosofi yang mempelajari nilai-nilai sensoris yang kadang dianggap sebagai penilaian terhadap sentimen dan rasa. Estetika merupakan cabang yang sangat dekat dengan filosofi seni.

Estetika dalam berpakaian, merupakan konsep yang dibentuk oleh masyarakat yang melahirkan bentuk- 
bentuk baju kurung yang berdasarkan adat dan syariat Islam untuk menutup aurat.

Estetika dalam berpakaian ini terdiri dari dua konsep yaitu konsep adat dan konsep Islam. Sebelum lahirnya Islam, konsep yang dikenal oleh masyarakat melayu adalah konsep adat. Hal ini dikarenakan konsep adat dan budayalah yang lahir terlebih dahulu dalam masyarakat melayu sebelum adanya Islam. sehingga estetika berpakaian hanya berdasarkan konsep adat saja berdasarkan kebutuhan dan kelaziman, hanya menutup bagian-bagian tertentu saja dari tubuh perempuan seperti pakaian kemben (Hartati et al, 2020). Namun ketika masuknya Islam di tanah melayu maka estetika berpakaian menggunakan konsep Islam berlandaskan syariat dan falsafah "adat bersendikan syara', syara' bersendikan kitabullah. Adat mengato, syara' memakai." Dalam hal tersebut adalah keharusan menutup aurat.

Dalam pemakaian ragam baju kurung sebagai warisan budaya melayu tak terlepas dari estetika dan artistika. Jika estetika merupakan konsep yang dibentuk oleh masyarakat yang melahirkan bentuk-bentuk baju kurung yang dimodifikasi sesuai dengan etika Islam dan perkembangan jaman. Maka artistika merupakan suatu keindahan yang tampak atau yang terlihat sesuai dengan kaidah dan etika berlaku dalam masyarakat.

Jika dahulu pakaian hanya berfungsi sebagai alat pembungkus atau pembalut yang melindungi tubuh dari udara dingin maupun udara panas atau pun gigitan serangga, maka dengan perkembangan Islam di tanah melayu, baju kurung tradisional perempuan melayu Jambi bukan lagi hanya berfungsi sekadar membalut aurat secara adat tapi juga membungkus aurat sesuai dengan etika dan estetika dalam adat dan agama Islam. Dimana terdapat aturan-aturan dalam kaidah berpakaian secara etika dan estetika yaitu harus longgar tidak memperlihatkan lekuk tubuh perempuan yang menjadi aurat, bentuk lurus kebawah, tangan bersiba dan bahan yang digunakan juga harus nyaman dan tidak transparan, hingga tidak membatasi gerak aktivitas perempuan melayu. Secara estetika juga tetap terlihat indah dan anggun.

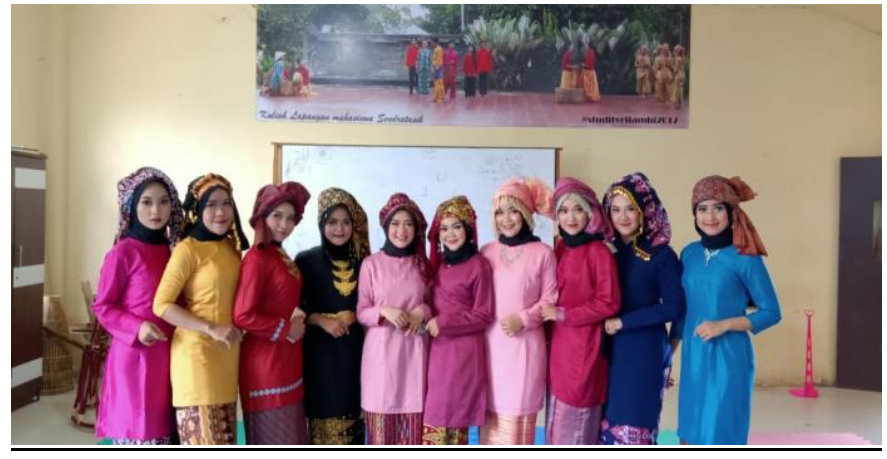

Gambar 4. Baju Kurung Perempuan Melayu Jambi Lengkap dengan Aksesoris
Keterangan: keindahan baju kurung perempuan melayu Jambi lengkap dengan aksesoris yg dipakai, penutup kepala jilbab dan tengkuluk, serta kain batik atau songket sebagai bawahannya. Dok. Pribadi.

Untuk melengkapi keindahan dari pemakaian baju kurung maka perempuan melayu Jambi melengkapinya dengan berbagai aksesoris dan kain yang indah. Pemakaian baju kurung bisa dipandankan dengan kain sarung batik maupun songket sebagai bawahannya dan tengkuluk kain batik/songket sebagai penutup kepala, bisa juga dipadukan dengan rok/celana panjang sebagai bawahan dan jilbab sebagai penutup kepala.

Saat ini perkembangan pakaian perempuan melayu terus berkembang sesuai dengan perkembangan jaman. Meskipun demikian perempuan melayu Jambi tetap melestarikan pemakaian baju kurung dalam kehidupan mereka hal ini terlihat masih banyaknya perempuan melayu Jambi yang memakai baju kurung pada acara-acara resmi formal maupun non formal, seperti acara pesta pernikahan, festival budaya, acaraacara adat dalam tatanan kehidupan masyarakat melayu Jambi maupun dalam kehidupan sehari-hari dengan berbagai warna dan corak yang indah tanpa melanggar etika dan estetika baik secara adat maupun secara syarak syariat Islam, hal tersebut sesuai dengan filosofi baju kurung yang melekat dengan kata "dikurung" yang berarti pemakainya terikat secara adat dan secara syara' yaitu syariat Islam dalam etika maupun estika berpakaian.

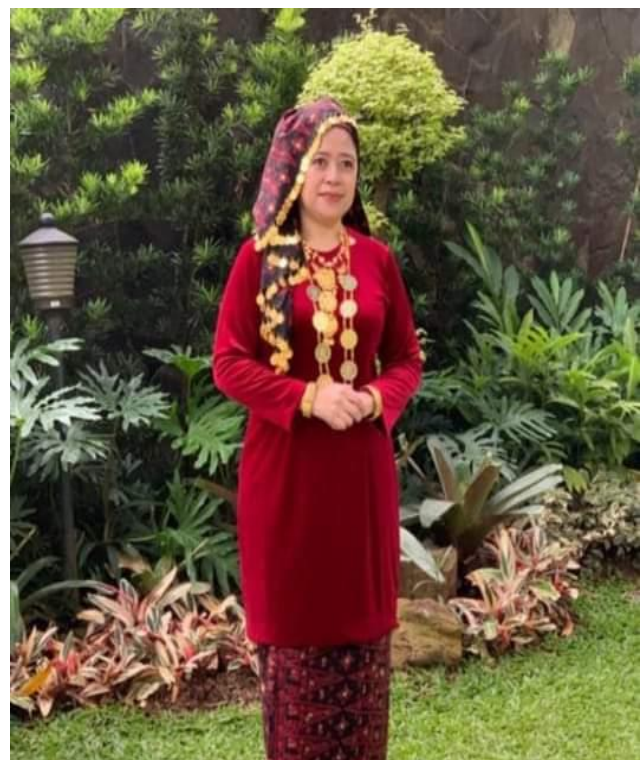

Gambar 5. Pakaian Adat Tradisional Perempuan Melayu Jambi

Keterangan: Puan Maharani ketua DPR RI memakai baju kurung pakaian adat tradisional perempuan melayu Jambi dalam acara HUT kemerdekaan RI ke-75 pada tgl 17-08-2020 lengkap dengan tengkuluk dan sarung batik Jambi. Sumber foto dari google. 


\section{SIMPULAN}

Pakaian merupakan bagian penting dalam kehidupan masyarakat melayu Jambi. Pakain merupakan cerminan diri seorang pemakainya. Baju kurung melayu merupakan cerminan keanggunan wanita muslimah dalam masyarakat melayu Jambi. Masuknya Islam ke tanah Melayu Jambi mempengaruhi semua aspek kehidupan bermasyarakat termasuk di dalamnya cara berpakaian masyarat juga menyesuaikan dengan syariat Islam sesuai filosofi dan falsafah adat melayu Jambi, adat bersendi syara', syara' bersendikitabullah, syara' mengato adat memakai. Semua tatan kehidupan tidak boleh bertentangan dengan syariat Islam yang mengacu pada Alqur'an dan hadist. Adat berpakaian pun harus sesuai dengan syariat baik secara etika maupun secara estetika.

\section{DAFTAR PUSTAKA}

Hartati M., Fatonah F., Selfi Mahat P. Estetika Ragam Tengkuluk Pakaian Tradisional Masyarakat Melayu Jambi. Jurnal Ilmiah Universitas Batanghari Jambi. Vol.20 no.2 (2020), 438 - 446. http://dx.doi.org/10.33087/jiubj.v20i2.896

https://id.wikipedia.org/wiki/Baju_kurung

https://id.wikipedia.org/wiki/Estetika, diakses tanggal 5 Juli 2019

Junaidi T Noor. 2010. Kearifan Busana Khas Melayu Jambi. Makalah. Mei 2010. Jambi, hlm.1.

Lembaga Adat Provinsi Jambi. 2001. Sejarah Adat Jambi; Pokok-Pokok Adat Pucuk Jambi Sembilan Lurah. Jambi: Lembaga Adat Provinsi Jambi.

Mardiani, Annisa. 2018. Asal Usul Pakaian dalam https://historia.id/asal-usul/articles/asal-usulpakaian. Diakses tanggal 10 juli 2020. Pukul 19.00 wib.

Nurhajarini, Dwi Ratna. Kain Kebaya dan Rok Pakaian Perempuan Yogyakarta Awal Abad ke-20. dalam "buku Sejarah Sosial, Konseptualisasi, Model dan Tantangannya" .Yogyakarta: Ombak, 2013.

Nurlaini. 2017. Tekuluk: Penutup Kepala Warisan Luhur dari Jambi. Edisi III. Jambi: Dekranasda Provinsi Jambi. 